\title{
Rapid Urbanization and Sustainability in Saudi Arabia: The Case of Dammam Metropolitan Area
}

\author{
Antar A. Abou-Korin ${ }^{1} \&$ Faez Saad Al-Shihri ${ }^{1}$ \\ ${ }^{1}$ Department of Urban \& Regional Planning, College of Architecture \& Planning, University of Dammam, Saudi \\ Arabia \\ Correspondence: Antar A. Abou-Korin, Dept. of Urban \& Regional Planning, College of Architecture \& Planning, \\ University of Dammam, P.O. Box: 2397, Dammam 31451, Saudi Arabia. Tel: 966-5-4788-5140. E-mail: \\ aaaboukorin@uod.edu.sa
}

Received: August 7, 2015 Accepted: August 26, 2015 Online Published: October 24, 2015

doi:10.5539/jsd.v8n9p52 URL: http://dx.doi.org/10.5539/jsd.v8n9p52

\begin{abstract}
Rapid urbanization is a characterizing feature of urban change in Saudi Arabia, especially in its large metropolitan areas such as Riyadh, Dammam Metropolitan Area (DMA), Jeddah and Makkah. Such rapid urbanization has created many urban problems that contradict with the principles of sustainability.

The paper argues that "Urban Sustainability" is a necessary policy in the case of DMA, and tries to define the needed approaches and actions to implement such policy in the region. In doing so, the paper starts by highlighting the rapid rate of urbanization in the Saudi Arabia in general; and in DMA in particular. Then, the paper presents an analysis of the unsustainable urbanization practices and problems in DMA. The paper then presents a literature review about sustainable urbanization approaches and requirements, focusing on developing countries. Finally, the paper recommends the necessary approaches and actions to achieve the proposed "Urban Sustainability" policy in DMA.
\end{abstract}

Keywords: rapid urbanization, urban sustainability, Saudi Arabia, Dammam Metropolitan Area

\section{Introduction}

Although urbanization is widely seen as a tool for economic growth, and cities as engines for economic development, rapid urbanization has adverse impacts. This is especially true in the case of developing countries where urbanization was unprecedented either in speed or scale. This is aggravated with the limited planning and management capacities of these countries and resulted in many unsustainable impacts and problems.

The UN report "World Urbanization Prospects, 2014" predicts that an additional 2.5 billion people will live in urban areas by 2050 , highlighting the need for a successful urban planning agenda and greater attention to be given to smaller cities where nearly half of all people currently reside (UN, DESA. 2014). The report expects that about two-thirds of the world population will live in cities by 2050 , with $90 \%$ of growth taking place in the developing countries.

In Saudi Arabia, urbanization is exceptionally rapid, especially in large metropolitan areas, such as Dammam Metropolitan Area (DMA). Such rapid urban growth has had many unsustainable impacts in these metropolitan areas. Therefore, this paper tries to investigate the rate and scale of urbanization in DMA, and tries to analyze its unsustainable impacts on the development process in the region. Also, it aims to define the necessary approaches to achieve sustainable urbanization in DMA.

In discussing this issue, the paper is divided into three main parts. In the first part, the paper presents an empirical analysis of the pace and size of urbanization in KSA in its regional context; and in DMA, as an example of Saudi metropolitan areas. Second, the paper presents a detailed analysis of the main unsustainable impacts of rapid urbanization in DMA. Third, the paper presents a literature review about the meaning and requirements of sustainable urbanization, as well as the impacts of rapid urbanization on urban sustainability. And finally, the paper presents some recommended approaches to achieve sustainable urbanization in DMA.

\section{Rapid Urbanization in KSA: Regional Comparisons}

In the global context, urbanization in KSA was very rapid and massive during the last five decades. According to 
the United Nations' report "World Urbanization Prospects, 2014", urbanization in KSA is higher than that of many of the most-populated Arab countries, such as Egypt, Iraq, and Syria. Figure 1 depicts that urbanization in KSA has jumped from the third lowest in 1950 to the third highest in 2000, and is expected to continue at that rank till 2050.

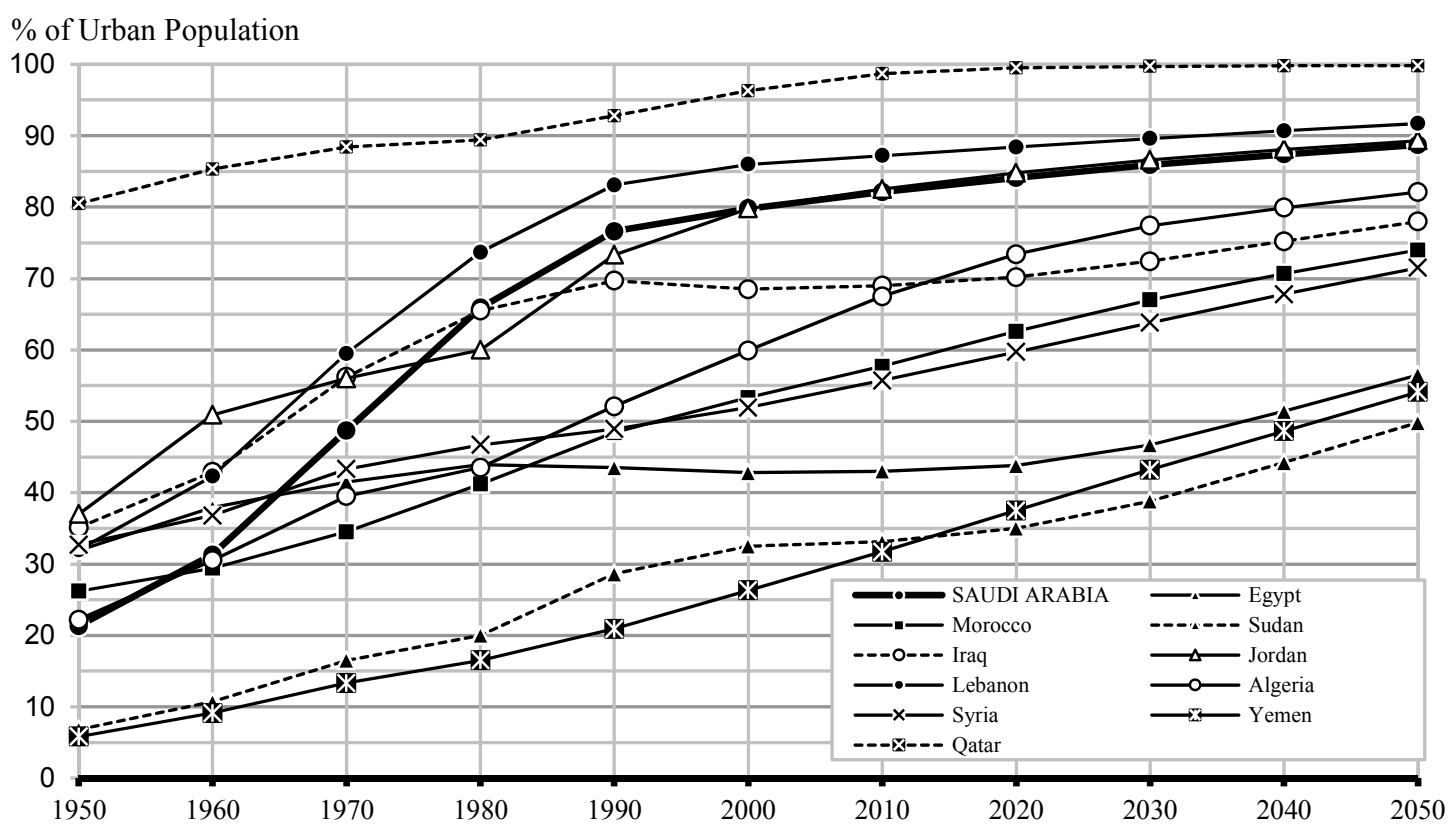

Figure 1. Percentage of urban population in KSA compared to Arab Countries

Note. Prepared by the researcher, data from: UN DESA. World Urbanization Prospects, 2014

The percentage of urban population in KSA has jumped from about $20 \%$ in 1950 up to $80 \%$ in 2000 , and is expected to reach about $90 \%$ in 2050 (UN DESA, 2014). Moreover, the urban population of the Kingdom has increased from just 665 thousand in 1950 to 24.8 million in 2015, with an increase of 24.1 million; doubling 36 times in 65 yeas. The urban population of the Kingdom is expected to reach 35.8 million by 2050, with an expected increase of about 11.0 millions in the next 35 years, which is about $45 \%$ of Kingdom's urban population today.

The main challenge here is that the Kingdom needs to build, in the next 35 years, about half of all cities available today in the Kingdom. To put it simply, the Kingdom needs to build 44 new cities, each of 250,000 inhabitants; a city every 9 months from now on till 2050.

Most of this massive increase in urban population is expected to take place in large metropolitan areas of the Kingdom; which means that urban problems in these metropolitans will get worse. This is a matter that necessitates immediate adoption of sustainable urbanization measures for accommodating such a huge increase of urban population expected in these metropolitan areas.

\section{Dammam Metropolitan Area: A Fast Growing Metropolis}

Dammam Metropolitan Area (DMA) is the third largest conurbation in the Kingdom of Saudi Arabia (KSA) and the main urban agglomeration in the Eastern province. Dammam Metropolitan Area (DMA) is formed by the adjacent cities of Dammam, Khobar, Dhahran and the developing area of Aziziyah and Half Moon south of Khobar. Greater Dammam includes Dammam Metropolitan Area (DMA) and the neighboring towns of Qatif, Safwa and Ras-Tanura (Figure 2). The total area of DMA is around 380,000 ha, housing about 1.8 million inhabitants.

The KSA economy is predominantly based on the exploration, extraction and processing of petroleum and the export of petroleum and petroleum-based products. The Eastern Province of KSA is the heart of Saudi oil production. Consequently, the economy and the physical development of DMA are mainly dependent on petroleum industry. 
DMA is connected to the Kingdom and the outside world with one international airport (King Fahd International Airport) and a freight seaport (King Abdulaziz Port) on the Arabian Gulf. Another port at Ras Tanura nearby is used exclusively for exporting petroleum. DMA is also directly connected to the Kingdom of Bahrain with a 25 $\mathrm{km}$ long King Fahd causeway. Jubail Industrial City is located in close proximity, less than $80 \mathrm{~km}$ to the north of Dammam. The capital Riyadh is some $400 \mathrm{~km}$ to the west. Express highways connect DMA to Riyadh and other Saudi cities and neighboring states of Kuwait, UAE and Oman. It is connected by a railroad to the capital Riyadh, and future rail projects are planned to connect adjoining Gulf Cooperation Council member states.

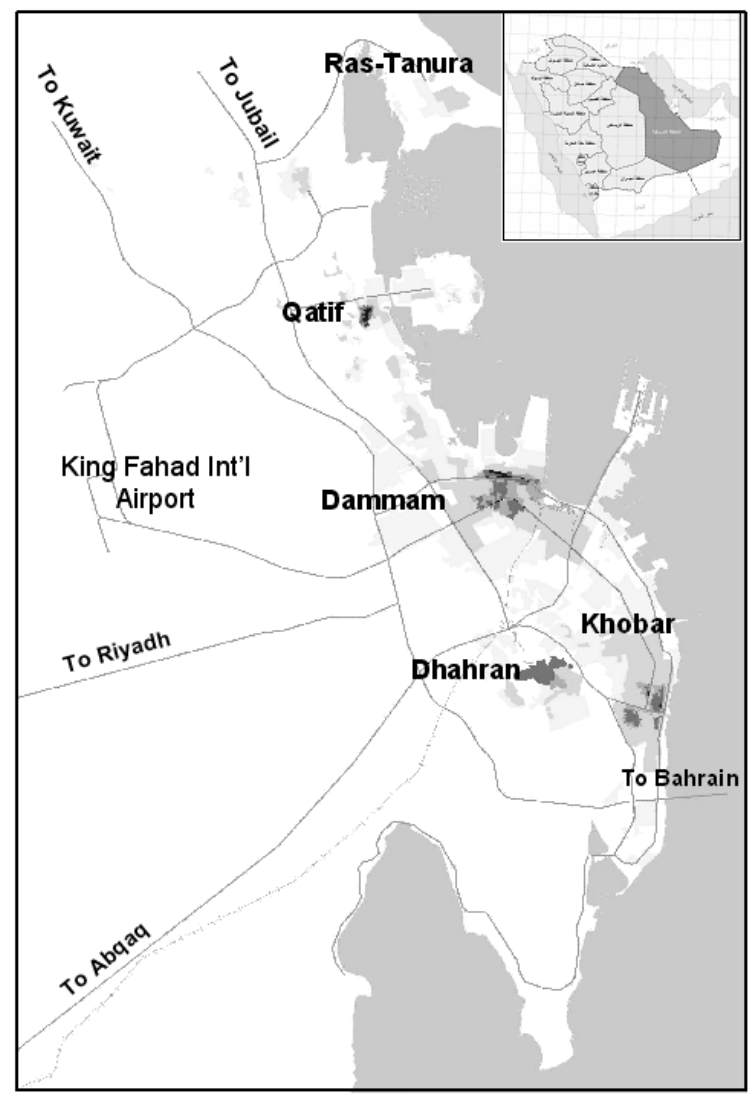

Figure 2. Dammam Metropolitan Area: Components and external connections

Note. Prepared by the researcher, data from: MOMRA-KSA (2007) and (CDSI, 2015).

\section{Urban Population Growth in DMA}

Despite the short age of modern urban development in DMA, urban growth has been very rapid. DMA population has increased from 0.365 million inhabitants in 1974 to 1.3 million in 1993, and to 1.75 million in 2004, and 1.8 million in 2010. The population of DMA has doubled five times in 35 years, from 1975 to 2005 . Under current population growth rates, DMA population is expected to reach 3.25-3.62 million people in 2040, with an increase of about 1.5-1.9 million people in next 25 years (Figure 3). 


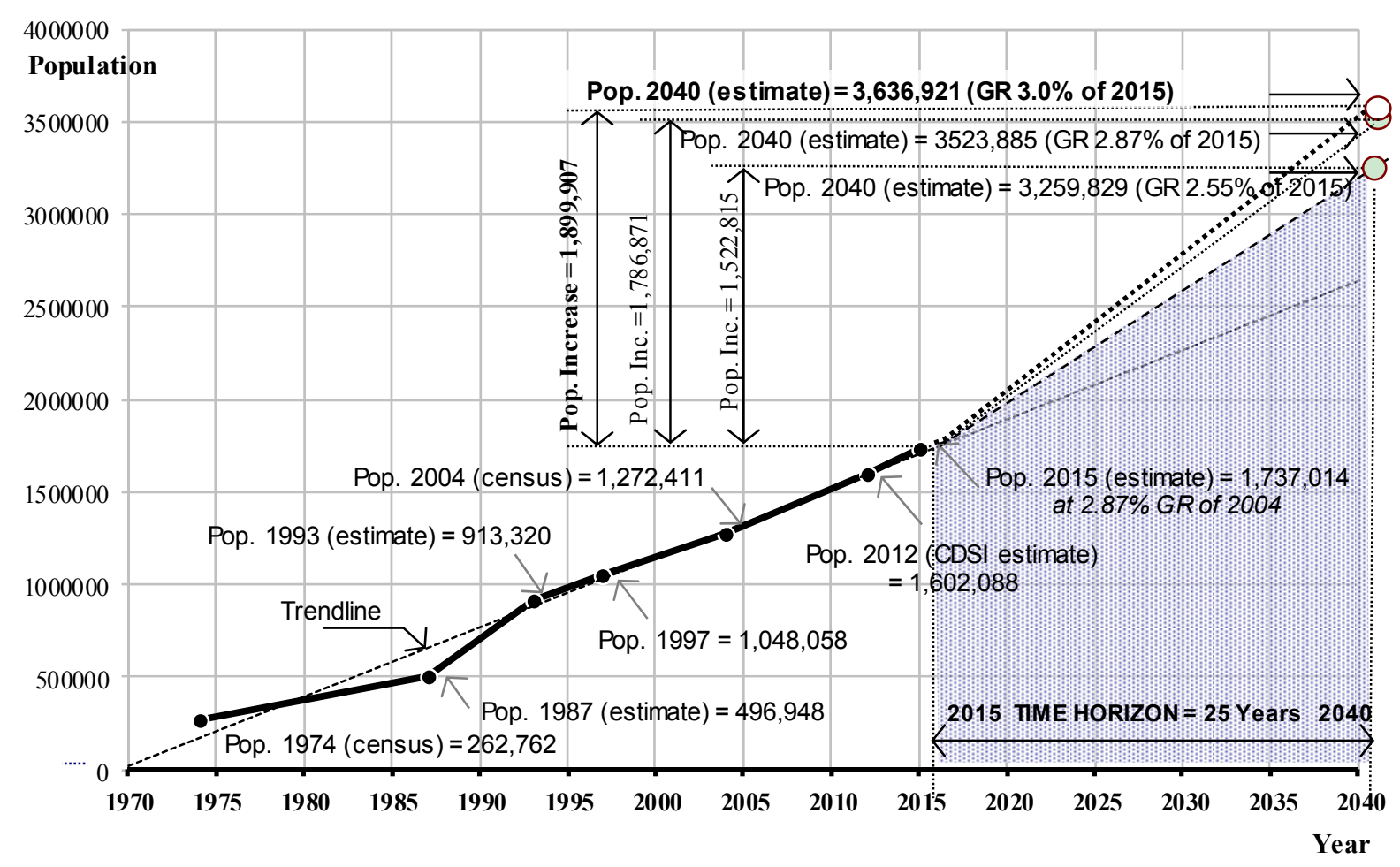

Figure 3. History and projection of population growth in DMA region: 1974-2030

Note. Prepared by the researcher, data from: MOMRA-KSA (2007) and (CDSI, 2015)

In projection of future population in DMA by 2040, three different scenarios can be proposed. First, using the national population growth rate of $2.55 \%$, would lead to a lower bound of projected population. Second, using the current regional growth rate of $2.87 \%$ can be considered as an intermediate scenario. Third, using a rounded growth rate of $3.0 \%$ can be considered as the upper bound scenario.

Since huge governmental investments in infrastructure and private investment in commerce and industries are highly expected to continue at high rates in the region, the upper bound scenario of expected population growth is more likely to be reasonable. According to this scenario, the population of DMA is expected to more than double in the next 25 years, reaching about 3.63 million in 2040, with a population increase of about 2 millions, which is more than the double of DMA population in 2015.

\subsection{Rapid Contiguous Agglomeration of Urban Area: Beyond the Urban Limit}

Associated with the rapid increase of urban population, there is a rapid contiguous growth of the urban area in DMA, leading to the formation of an agglomerated urban mass. The urban area of DMA has rapidly grown from just 2,096 hectares in 1973, to 8762 hectares In 1982, to 16,148 hectares In 2004, and is expected to reach 20,368 hectares in 2015, doubling 10 times in 40 yeas. The important point here is that such growth in urban areas was contiguous, spreading out of the old urban centers. This has led to the formation of an agglomerated urban mass in DMA. Moreover, most of that growth was unplanned and beyond urban limits set by Dammam Urban Planning Department.

\subsection{Factors behind Rapid Urbanization in DMA}

DMA is growing fast not only in terms of population, but also in terms of its physical development. The three main factors that are promoting this growth may be identified as: (a) the rapid expansion of the economy (b) the speculative real-estate market and (c) the limited capacity of Dammam Urban Planning Department (DUPD) in devising and imposing urban regulations (Abou-Korin, 2011).

\subsubsection{Rapid Expansion of the Economy and Obsession with Housing}

The growth of DMA is closely related to the growth of petroleum sector in KSA. Dhahran is the headquarters of Saudi Aramco, the national oil company. A large proportion of population in DMA works at Aramco or in other 
petroleum-related business activities. With the expansion of petroleum exploration and petrochemical industries, and investment in infrastructure and services, new employment opportunities are constantly being generated. Also, the average household income in DMA is very high, more than $\$ 3000$ per month.

This has resulted in an ever increasing demand for housing stock. Due to different factors, supply of housing can hardly keep pace with the rising demand. This has resulted in constantly increasing housing rent and price levels. Due to lack of alternative options for investment by the ordinary citizens, investing in housing has become the preferred option for many of them. Private sector companies have followed the same trend investing heavily into housing sector.

\subsubsection{Speculative Land Market}

The private sector plays a vital and dominant role in the economy, including land development projects. It also acts faster than the municipalities, which, with their regulatory functions, are sometimes more reactive than proactive. The private sector is developing and subdividing huge tracts of land in the outskirts with scant regard for city planning, promoting urban sprawl in the process. Agricultural land has been encroached upon and ecologically sensitive land along the Arabian Gulf coast has also been targeted for development. There has also been land filling along the coast with little consideration for the adverse environmental impacts. These companies often seem to enjoy significant political support as evidenced from the exceptions made to planning regulations in their favor by the regulatory authorities. Indiscriminate land development is a threat to sustainable urban development.

The large tracts of land developed and subdivided have witnessed very sparse development, but that has not stopped either the flow of investment or the escalation of land price. This implies that land speculation is the driving motive for the investors in land. This trend contributes to the rising cost of housing in DMA. Land is being withheld from development (construction) while the demand for land for housing development is on the rise. The government of Saudi Arabia has of late decided to introduce a vacant land tax to curb this phenomenon.

\subsubsection{The Limited Capacity of Dammam Urban Planning Department (DUPD)}

Despite the rapid pace of urban growth in DMA, the capacity of Dammam planning department was very much lacking. Before 1972, planning activities in the Eastern Province, including DMA, was the responsibility of City Planning Office affiliated to Ministry of Interior's Deputy for Municipalities. In 1972, city planning office was founded in the Eastern Province. In 1983, Directorate of Municipalities and Rural Affairs was founded in the Eastern Province. In 1986, Dammam Municipality was upgraded to Eastern Province Amana. Since then, urban management in DMA is the main responsibility of Dammam Urban Planning Department "DUPD", Dammam Municipality, with support of the City Planning Department at the Ministry of Municipalities and Rural Affairs (MOMRA).

Despite its limited resources of qualified and experienced manpower, DUPD has been assigned with 19 big tasks that are very much beyond its capacity (Municipality of the Eastern Province, KSA, 2008). DUPD has no more than 15 of mostly newly graduated planners and architects distributed in four big units: urban planning, project management, development control, and surveying. On the other hand, there is an increasing demand for services from DUPD.

In an effort to support Dammam Urban Planning Department (DUPD), Eastern Province Amana has recently (in 2014) established a local urban observatory in DMA. This observatory is expected to support DUPD through providing updated and reliable urban data (Eastern Province Amana, KSA. 2014).

\section{Unsustainable Urban Impacts of Rapid Urbanization in DMA}

Urbanization is the most profound human alteration of the natural environment through a wide range of urban land use activities (Ujoh, et al., 2010; Ifatimehin and Musa, 2008). These activities include, but are not restricted to, transportation, commercial, industrial, residential, institutional, and recreational land uses. The proliferation of urban centers, and their associated environmental and socio-economic impacts, has been phenomenal from the turn of the 20th century (Lambin et al., 2003; European Environment Agency, 2006; Garba, 2004; Abou-Korin, 2011).

In DMA, rapid, and often poorly regulated, urbanization has adversely impacted the natural environment. Some of these unsustainable impacts of urbanization in DMA are described below.

\subsection{Urban Expansion on Agricultural Land and by Land-Filling into the Gulf}

Rapid urbanization in DMA has been associated with some serious unsustainable development practices. The rapid loss of agricultural lands and the destruction of marine life along the shores of the Arabian Gulf due to 
land-filling in Arabian Gulf waters are the most acute sustainability problems in the region.

\subsubsection{Expansion on Agricultural Lands}

Agricultural areas represent a valuable development asset, especially in this harsh desert environment. In addition to its economic value, these highly fertile lands can not be replaced if lost. In addition, these agricultural areas have a historic value as it proves the historic role of the area in the development process through history. Moreover, these agricultural areas along with gulf waters and the extended desert background offer a unique, picturesque landscape and a natural integration rare to find elsewhere in the Kingdom. For these reasons, conservation of agricultural areas must be an indisputable objective, especially with the availability of vast desert areas around these agricultural areas (Abou-Korin, 2011).

Despite this, the "Executive Plans for Dammam Metropolitan Area" prepared for Dammam Municipality by CH2M Hill International and CEG in 1982, has permitted the approval of residential subdivision plans on agricultural land on the condition of getting an approval form the Ministry of Agriculture ( $\mathrm{CH} 2 \mathrm{M}$ Hill International and CEG, 1982).

Based on this, urban expansion on agricultural areas has sharply increased. During the period 1982-2003, urban expansion has consumed 2,200 hectares of highly productive agricultural land in Qatif area and 420 hectares in Dammam area (MPMR, KSA, 1982; Quick Bird, 2003). Figure 4 depicts the spatial distribution of cultivated areas in DMA during the same period.

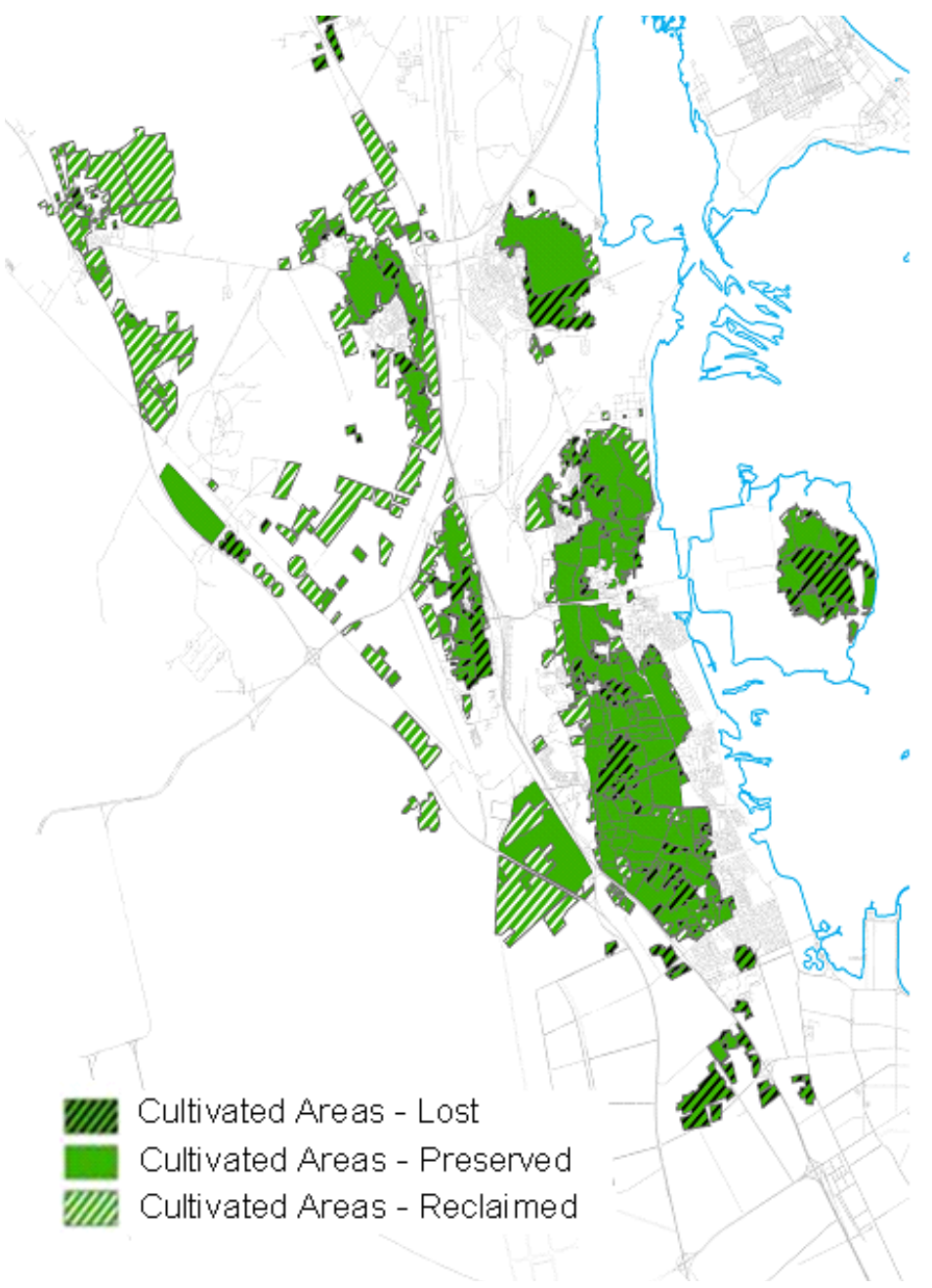

Figure 4. Distribution of lost, preserved, and reclaimed agricultural areas in DMA 1982-2003

Note. MOMRA-KSA (2007).

\subsubsection{Land-filling in Gulf Waters}

Despite the fact that land-filling is one of the most disruptive activities to coastal and marine resources, 
reclamation of inter-tidal areas continues apace and on a large-scale. Land speculation in general and the premium prices available for seafront property in particular appear to be the key drivers behind the environmentally destructive land-filling that has devastated most of the coastline.

Through comparing DMA satellite images for years 1982 and 2003, land-filling during this period has covered an area of 6500 hectares in Gulf waters. Moreover, there are many subdivision plans that are approved to be built on Gulf water with an area of about 5,300 hectares (MOMRA-KSA, 2007). Figure 5 presents the area and spatial distribution of current and expected land-filling in Gulf waters.

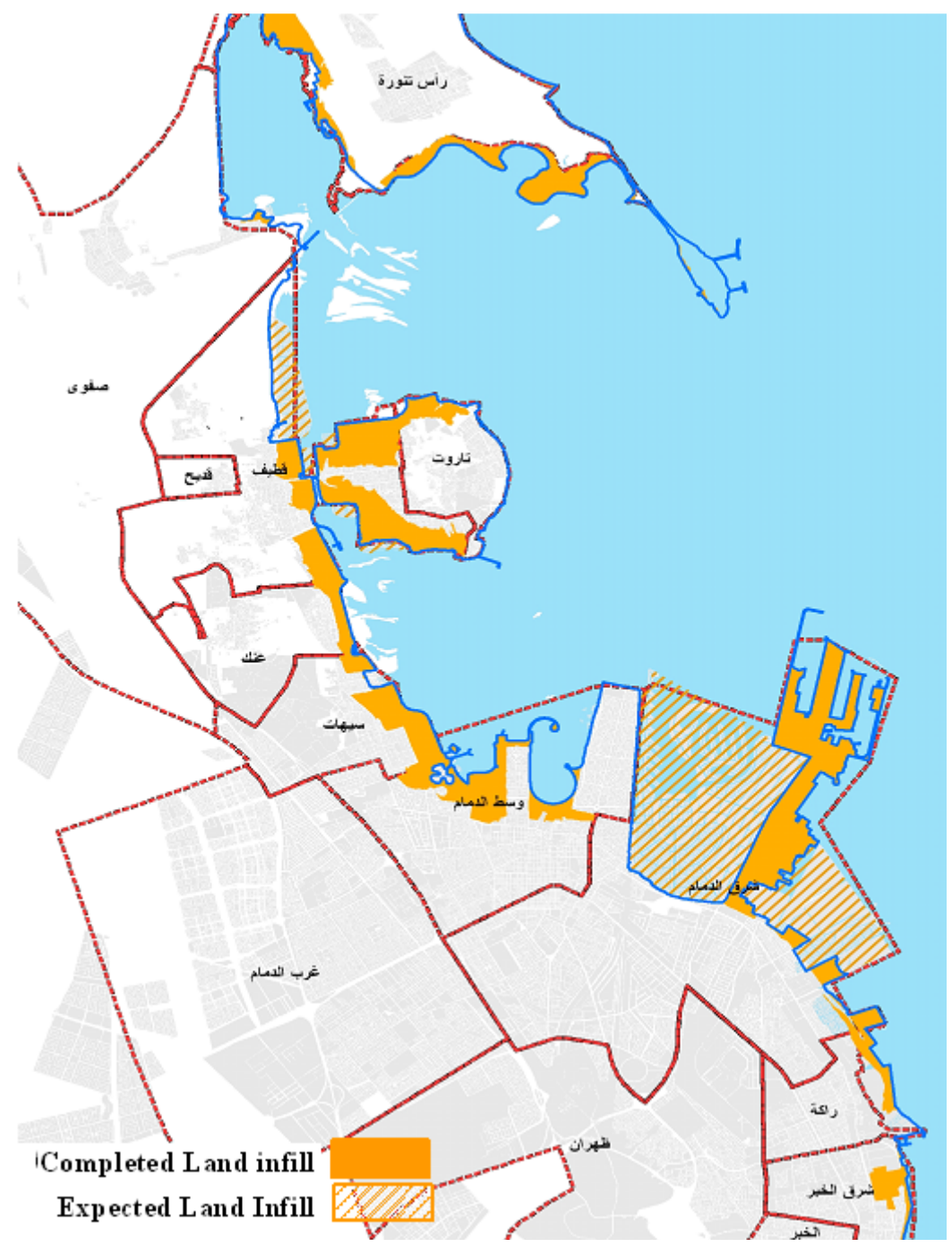

Figure 5. Spatial distribution of completed (1982-2003) and expected land-filling activities

Note. MOMRA-KSA (2007).

From the economic point of view, land-filling is a very costly activity compared to the cost of desert land reclamation and results in very high prices of land. In addition, foundation and construction costs in these landfill areas are very high. In addition, and due to land-filling activities, the amount of Saudi fishing from the Arabian Gulf has declined from 26,000 tons in 1998 to 21,000 in the next year. Such decline was acute in shrimp fishing that sharply declined from 6,000 tons in 1998 to only 2,000 ton in 1999 (Ministry of Agriculture, KSA, 1999).

Whilst attempts to control land-filling practices date back to the 1970s, when the corniche development expected to provide a permanent coastline, this program appears not to have been effective. Therefore, a renewed commitment by all key decision makers is now required in attempt to remedy this.

\subsection{Urban Sprawl - Agglomerating Contiguous Urban Mass}

Urban sprawl is a major problem associated with the rapid development of DMA. The contiguous spatial 
expansion of DMA has been extensive, outpacing the growth of population, resulting in sprawling, low density development. In 2003 , only 8,900 out of 25,618 ha of land within the urban boundary (35\%) was developed, leaving 16,700 ha of vacant land.

The density of population in DMA was only 64 persons/ha in 2003. This is very low compared to the figures from other cities in developing countries. Moreover, the density is falling even further in many parts of the region. Over the three decades from 1972 to 2003, the density of the largest city of DMA, Dammam, had decreased by $46 \%$. This trend is expected to continue and the density in DMA is expected to precipitate to a level of only 35 persons/ha by 2030 (MOMRA, 2007).

Another important feature of urban sprawl is the low rate of land development in approved subdivisions. A high percentage of these lands is still vacant, especially in subdivisions located away from city centers. In 2003, about $50 \%$ of land allocated for urban activities in Dammam Metropolitan, was still vacant (MOMRA-KSA, 2007).

This high level of urban sprawl and the remarkable decline in overall population density have had many negative impacts on development process in DMA, which can be summarized as:

- Because of rapid and massive urban sprawl, urban area has expanded to include many of incompatible uses such as gas and oil lines, the military base in Dhahran, and sheep and camel markets. These incompatible uses are of major threat to the urban environment and create many serious environmental and traffic problems inside the urban area.

- Urban sprawl has consumed most of the land suitable for urban development in DMA. Most of these lands have been allocated for residential purposes, which has created two serious problems. First, there is not enough land left to meet future development needs. Second, these approved subdivisions, though vacant now, constitute major development constraints in formulating future urban development plans in DMA.

- Development of these sparsely populated subdivisions, especially regarding the provision of infrastructure and public services, is very much costly and un-economic.

- These sparsely populated areas constitute a burden on local municipalities, especially regarding garbage collection and the maintenance of the very long infrastructure networks.

According to MOMRA-KSA (2007), the vacant land inside the approved urban limit in 2004 was about 34,000 hectares. This area, at the average overall density prevailing in built-up area, which is about $66 \mathrm{p} / \mathrm{hectare}$, could accommodate about 2.3 million inhabitants. This is while the expected population increase till 2030 is less than 2.0 million. This clearly demonstrates that urban sprawl is much greater than the need of current and future generations in the region.

In 2015, the Saudi Ministry Cabinet approved a tax on undeveloped land within the urban boundary to control urban sprawl (Alriyadh Newspaper, 2015). This action is expected to control land speculation activities.

\subsection{Urban Regulations - Legalizing the Sprawl}

Land use and building control regulations and systems applied since 1976 have facilitated sprawl in DMA. $92.5 \%$ of areas have been approved for low-density detached houses with a height limit of two floors. This has resulted in the requirement for a higher amount of land for residential purposes.

Despite the high level of household income in DMA, the price of these detached houses, locally known as villas, are beyond the means of a large section of the population, particularly the young and those engaged in low-paying jobs. Moreover, a large percentage of the residents are foreigners who cannot afford the luxury of such houses.

There have been many instances where the regulations in force were waived or changed to allow development activities that were incompatible with the environment. Some of these development projects were at a very large scale. This created many environmental and traffic problems.

\subsection{Agglomerating Contiguous Urban Mass}

Another serious problem associated with urban sprawl in DMA is it takes a form of successive contiguous waves of growth leading to an agglomerating urban mass.

On the other hand, the contiguous growth of urban area in DMA is expected to lead to an agglomerated contiguous urban mass, which will further aggravate the urban decay and traffic congestion at the central areas of most of DMA cities. In 20 years to come, and after intensification of landuse and the expected high increase in population and activities in this contiguous urban mass, urban environment, infrastructure, and traffic will be 
severely deteriorated.

\subsection{Large-Scale Urban Projects - "Cities within Cities"}

Many large scale land development projects have emerged over the last four decades. Some of these are located on reclaimed land, in Aziziyah and the Half Moon Bay area, and around the international airport. For example, the King Fahd suburban area comprises of 3,613 ha of land, and Al-Naseem covers 3,339 ha of land. At the current population density, they can accommodate 230,000 and 213,000 people respectively (MOMRA-KSA, 2007). Some of these projects are bigger than some existing cities in DMA, growing as 'cities within cities.' These developments are expected to present significant environmental, traffic, and infrastructure impacts.

\subsection{Incompatible Land-Uses - Environmental \& Economic Unsustainability}

Planners of DMA had generally failed to foresee the pace of urban expansion, and incompatible land uses that were located safely beyond the urban limits have now become surrounded by urban development due to rapid urban growth. These incompatible land uses include the Dhahran military base, oil pipelines, high-tension power lines, animal markets, garbage disposal and treatment facilities etc. (MOMRA-KSA, 2007). Some of these land uses pose health risks to the urban residents or are visually disturbing for the environment.

\subsection{Unsustainable Housing Patterns}

Housing sustainability is very crucial because of its direct effects on socio-economic conditions of city residents (Abdellatif and Othman, 2006). Although there are many housing sustainability problems in DMA, this paper focuses on housing patterns and costs of housing in DMA as they are crucial problems in DMA.

In DMA, there are lots of housing units; however, the problem is about the pattern of housing available. Most of the available housing units are either detached villas or spacious apartments, which are beyond the economic capacity of the youth and middle-class Saudis. Also, this pattern exceeds the actual needs of many Saudis, taking into account the apparent decrease in the size of the Saudi family. The average size of Saudi family has declined from 7 in 1996 to about 6 in 2004 (in just 7 years), and is expected to continue declining. Also, the analysis of population age structure in DMA showed that about $44 \%$ of the population is under the age of 20 ; and about $61 \%$ of the population is under the age of 30 . This means that there will be an increase in the number of new families, which usually will be of small-size for a considerable period of time. The analysis of socio-economic survey conducted in DMA in 2005 revealed that about $52 \%$ of families in DMA are living in leased apartments. But, among married people under the age of thirty, about $80 \%$ live in leased apartments.

On the other hand, the analysis of approved subdivisions that are still vacant shows that most of land parcels are of large areas. About $83 \%$ of land parcels in these subdivisions are of areas between 500-2,000 m2, which is far beyond the financial capacity of most of the new families.

\section{Urban Sustainability and Rapid Urbanization: Literature Review}

The speed and sheer scale of urban growth in developing countries presents dreadful challenges for urban planners and policy-makers in these countries. Rapid urbanization in the developing world is highly beyond the capacity of most of its cities. Based on available data, the proportion of urban poor is increasing faster than the overall rate of urban population growth. An estimated 72 per cent of the urban population of Africa, 43 per cent for Asia and the Pacific, 32 per cent for Latin America and 30 per cent for the Middle East and North Africa, are now live in slums (Cohen, B. 2006). Yet, each year cities attract new migrants who, together with the increasing native population, expand the number of squatter settlements and shanty towns, exacerbating the problems of urban congestion and sprawl and hampering local authorities' attempts to improve basic infrastructure and deliver essential services. This problem is aggravating and getting more severe in developing countries, where cities have been growing without a concomitant expansion of economic activity (UN, Economic and Social Council. 2014). Thus, "sustainable urbanization" concept is regarded as a process that aims to manage urbanization to overcome the mounting problems associated with rapid urbanization.

Based on the broad definition of sustainability, "urban sustainability" and "sustainable cities" are used to refer to cities and urban areas that have been able to integrate social and economic development with environmental management and urban governance (UN, 2013; UN Habitat and DID, UK, 2002). "Sustainable urbanization" is usually used to define a dynamic process aimed at achieving these sustainability conditions in the urban environment for both present and future generations by addressing environmental, economic, social and governance concerns (Roy, 2009; Shen et al., 2011). As urbanization process gets rapid, urban policymakers and planners, especially in developing countries, are confronted with mounting challenges of demographic, socioeconomic, environmental and institutional dimensions (UN Economic and Social Council, 2014). 


\subsection{Recommended Actions to Achieve Sustainable Urbanization}

To achieve sustainable urban development, the American Planning Association (APA) has developed a comprehensive list of actions that have to be taken by planners at local, regional, national levels. These actions can be categorized into sets of actions such as growth management, land-use, transportation, etc. (APA. 2000).

Regarding growth management actions necessary to attain sustainable urbanization, it is recommended to formulate appropriate development and population growth policies within the carrying capacity of natural systems and community facilities. Also, future settlement development patterns should respect natural systems. Moreover, growth management policies should be formulated so as to attain/maintain diversity in local populations and economies.

Regarding land-use actions necessary to attain sustainable urbanization, it is recommended to promote compact development through an integration of community activity areas within walking or bicycling distance. Also, it is recommended to guide and contain urban growth to existing developed areas, control urban expansion into outlying undeveloped areas and encroachment upon nature. This requires the development of vacant lands and 'brown field' sites, and to promote human-scaled development that is pedestrian-friendly and oriented around public transit. Also, development plans should be of a regional vision respecting the regional ecosystems and natural functions.

Regarding transportation actions towards urban sustainability, it is recommended to reduce the need for vehicle trips; and to promote infill and mixed use development. Public transportation is highly recommended to provide affordable, efficient transportation alternatives for everyone, especially low income households. Also, it is recommended to promote pedestrian and bicycle use, enhance access between neighborhoods, and to discourage use of cars.

For these actions to be implemented; it is important to involve local redisents in setting the development vision of their communities. Also, it requires enabling and encouraging residents to be aware of the environment and to reduce levels of consumption and waste generation and encouraging them to use public transportation.

\section{Proposed Approaches to Achieve Sustainable Urbanization in KSA: The Case of DMA}

Based on the above analysis of pace and scale, as well as causes and consequences of rapid urbanization in DMA, it has been evident that little attention has been paid regarding environment and development practices in terms of quality of urban environment and the urban needs of future generations. This highlights the need for the adoption of comprehensive sustainable urbanization policy in DMA, taking into account the environmental and socio-economic dimensions of sustainability.

In this regard, the paper recommends three necessary approaches to implement sustainable urbanization policy; urbanization should be within sustainable environment context; to build a distinctive identity for DMA, and to ensure sustainable functioning of urban environment (Figure 6).

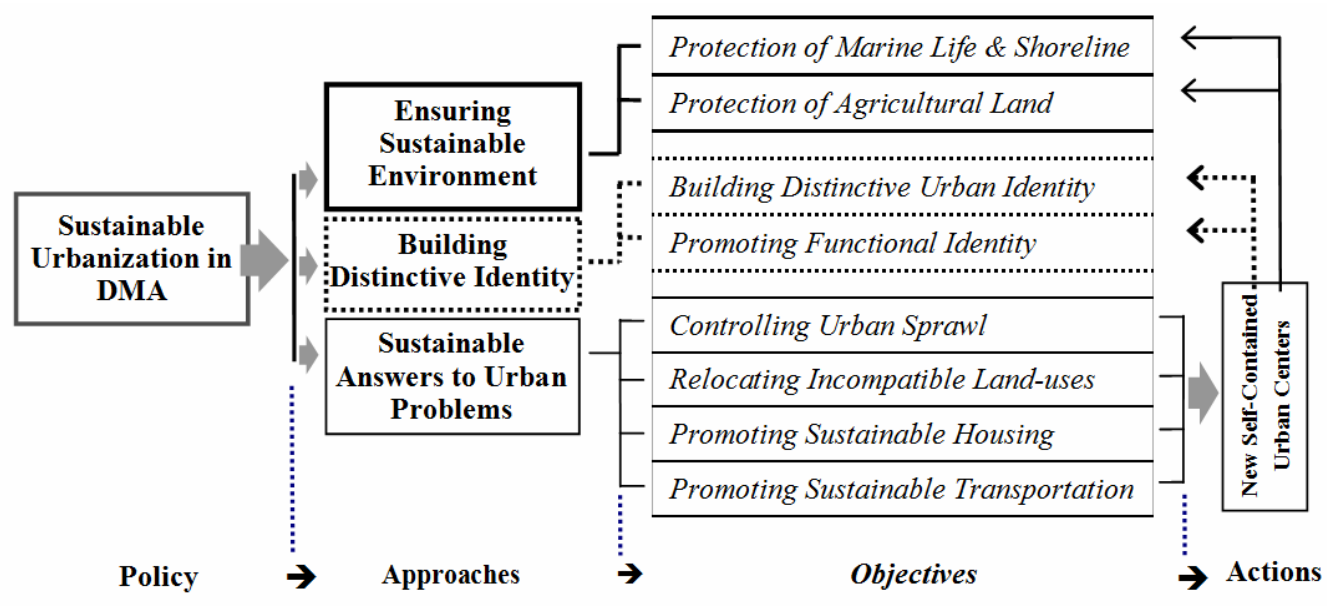

Figure 6. Approaches \& actions recommended to achieve sustainable urbanization in DMA

\subsection{Urbanization within Sustainable Environmental Context: Smart Growth}

Smart growth, within the scope of sustainability, is considered to be "a collection of land-use and development 
principles that aim to enhance the quality of life, preserve the natural environment and save money over time. Smart growth principles ensure that growth is fiscally, environmentally and socially responsible and recognizes the connections between development and quality of life. Smart growth enhances and completes communities by placing priority on compact development through infill, redevelopment and green space protection."(CNU, 2001; Al-Shihri, 2013).

DMA is surrounded by unique natural environmental elements, the Gulf water, the agricultural areas in Qatif, and the desert landscape. These natural components constitute crucial elements for the environmental and economic sustainability in DMA. Therefore, urban expansion should be managed so as not to endanger these valuable resources. Urban regulations should be articulated to prevent expansion on agricultural lands or into gulf waters. This requires immediate delineation of the shoreline and cultivated areas.

\subsection{Building Distinctive Identity}

It is the purpose here to create a unique and distinctive identity in DMA depending on its unique natural environmental resources and cultural heritage; and thus fulfilling the essence of sustainability. This paper recommends achieving such distinctive identity through promoting both functional identity and urban identity.

Regarding functional identity, it is recommended to develop regionally recognized activities in DMA that depend on its natural and environmental resources. DMA should be promoted functionally as a regional hub for recreational and commercial activities in the Gulf region. DMA has huge potentials to promote tourism and recreation activities in Aziziyah and Half-Moon area, along the gulf beach, and in agricultural and desert hinterlands. Also, large-scale commercial activities are also recommended in DMA.

Regarding urban identity, it is recommended to develop a regionally recognized urban identity. This requires building a unique urban image of the region depending on its unique natural resources and cultural heritage. Also, it is recommended to conduct visual upgrading of deteriorated urban areas and to build some unique visual landmarks. The main gates to the region must be visually promoted. To achieve these visual requirements, visual dimension should be taken into account when setting development and building regulations in DMA.

\subsection{Developing Sustainable Answers to Urban Problems}

In the light of the above stated unsustainable impacts of rapid urbanization in DMA, and to achieve sustainable urbanization in the region, it is recommended to overcome current urban and socio-economic problems in DMA. In doing so, the following actions are highly recommended (AbouKorin, 2013):

- Controlling urban sprawl: this requires delineation and imposing of an urban limit and development stages. Also, to prevent land speculation, tax must be imposed on vacant lands within the urban limit.

- Relocating of Incompatible land-uses out of residential areas.

- Improving efficiency and coverage of public services and urban utilities.

- Improving efficiency of transportation system

Since 2003, Saudi Arabia started pushing for more citizen participation in local affairs management through municipality councils (Alyaum Newspaper, 2003). This significantly helped in defining people needs and aspirations, and encouraged them to effectively participate in local community development activities.

\subsection{New Detached Self-Contained Urban Centers: To Prevent Contiguous Agglomeration}

The paper emphasizes the need to prevent the continuous contiguous growth of DMA as this will lead to further agglomerate the urban mass of DMA. This ever growing agglomeration of the urban mass has further increased the pressure on DMA central areas, and further aggravated environmental problems, urban decay and traffic congestion in these areas. Also, as this huge urban mass continues spreading, many of the incompatible uses that once were away from urban areas, have come to be with the urban area; and created a web of environmental and traffic problems as stated before. If this trend of urban growth were to continue in the next 20 years, the urban mass of DMA will be huge, and so will be the environmental and traffic problems.

Thus, the paper argues that new, independent and self-contained, urban centers are expected to have many advantages in the case of DMA. First, it will minimize the dependence of these centers' residents on the central areas of DMA. Second, it will disperse future population on a wider area, and thus minimize the problems of urban concentration. Third, some of these centers could be allocated for relocation of incompatible uses currently inside the built up area of DMA.

These approaches and actions have been defined based on the analysis of potentials and urban sustainability problems in DMA, and in guidance with sustainability principles and the national and regional development 
plans (Figure 7).

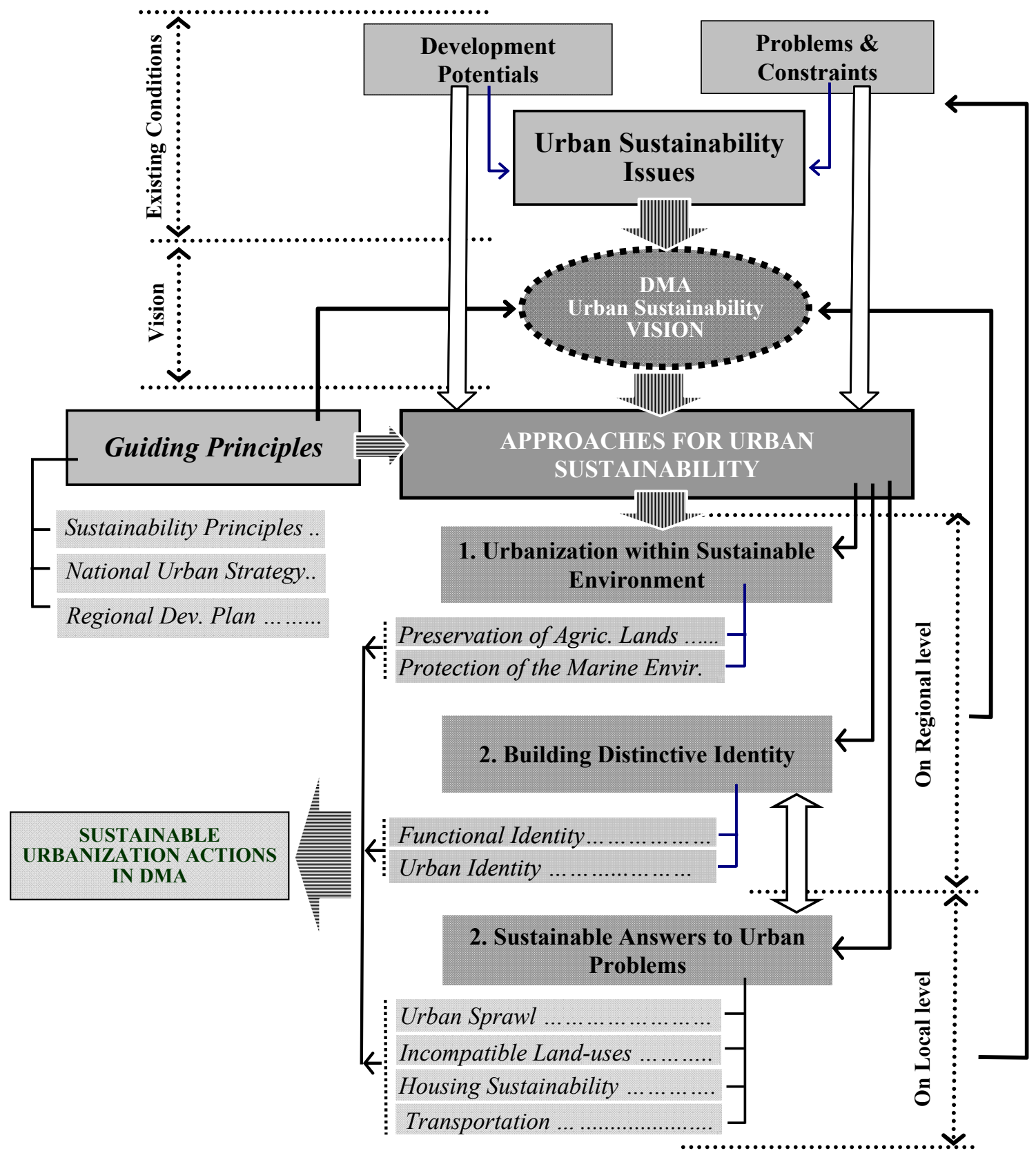

Figure 7. Linkages and interactions between sustainable urbanization approaches \& actions recommended in

DMA

\section{Summary and Conclusion}

Based on the extensive analysis of the main causes and consequences of rapid urbanization in DMA, the paper has defined two main unsustainable impacts of rapid urbanization in DMA: (1) urban expansion on agricultural land and by land-filling into the Gulf, and (2) unsustainable urbanization.

To rationally overcome these consequences, the paper proposes "sustainable urbanization" as a necessary policy for managing urban growth in DMA. The paper argues that "Sustainable Urbanization" policy in DMA should focus on three main issues: protection of the marine environment and agricultural lands, preservation of urban lands for future uses, and improving the urban environment.

For protection of marine environments, the paper recommends that shoreline limit should be precisely delineated in collaboration with Local Peoples Council. In addition, urban development regulations should prevent any 
urban activities beyond that limit and prevent any urban or industrial discharges into the Gulf water. More important, Local Peoples Council has to monitor and approve development activities along the shoreline.

Regarding protection of agricultural lands, the paper recommends that urban activities on agricultural land should be limited to private "non commercial" residential activities with an area of no more than $10 \%$ of the agricultural plot with a maximum area of $1,000 \mathrm{~m} 2$ and two-storey $(8 \mathrm{~m})$ height. Urban regulations have to criminalize any agricultural land degradation activities, and local authorities have to monitor and prevent such activities. Also, change of land use from agricultural to urban should be based on a report and recommendation from Ministry of Agriculture, and to limit new urban recreational activities to those with environmental impacts acceptable by the Ministry of Environment.

Regarding preservation of urban lands for future uses, the paper argues that controlling urban sprawl is the key issue in this regard. To achieve that objective, the paper recommends the prevention of urban activities outside the approved urban limit and that the approved urban limit should not to be expanded in the next 15 years. This is mainly because land available for urban use within the approved urban limit is enough to meet population needs in the next 20-25 years. However, to adhere to the principles of sustainable urbanization, population density in vacant and newly approved subdivisions should be increased. This may require imposing tax on undeveloped approved subdivisions to prevent land speculation.

Concerning overcoming environmental, traffic, and infrastructure problems in DMA, especially in congested city centers, the paper recommends that new large-scale residential and commercial projects are to be located in areas not in close vicinity of currently heavily-populated areas. Also, existing incompatible land-uses should be relocated outside the urban area of DMA. In this regard, the paper recommends stopping the contiguous spreading of the urban area through building new independent self-contained urban centers away from these congested urban centers.

\section{References}

Abdellatif, M. A., \& Othman, A. E. (2006, December). Improving the Sustainability of Low-Income Housing Projects: the Case of Residential Buildings in Musafafah Commercial City, Abu Dhabi, Emitates Journal for Engineering Research, 11(2), 47-58. Retrieved from http://www.engg.uaeu.ac.ae/ejer/

Abou-Korin, A. (2011). Impacts of Rapid Urbanisation in the Arab World: the Case of Dammam Metropolitan Area, Saudi Arabia. 5th Int'l Conference and Workshop on Built Environment in Developing Countries (ICBEDC 2011), At Universiti Sains Malaysia, 11800 Pulau Pinang, Malaysia

Abou-Korin, A. (2013, December). Small-Size Urban Settlements: A proposed Approach for Managing the Urban Future in Developing Countries of Increasing Technological Capabilities - The Case of Egypt. Ain Shams Engineering Journal. Retrieved from http://www.sciencedirect.com/science/article/pii/S209044791300124X

Alriyadh Newspaper, KSA. (2015). Saudi Ministry Cabinet Approves Tax on White Lands. Monday 2015/03/23.

Al-Shihri, F. (2013, July). Principles of Sustainable Development and Their Application in Urban Planning in Saudi Arabia. Journal of Engineering Sciences, 41(3), 2013.

Alyaum Newspaper. (2003). Saudi Ministry Cabinet approves more citizen participation in local affairs management. 24 October 2003.

APA (American Planning Association). (2000, April 16) Policy Guide Adopted by American Planning Association Chapter Delegate Assembly. New York. American Planning Association.

CDSI, Central Department of Statistics and Information, Saudi Arabia. (2015). Population Statistics. Retrieved from http://www.cdsi.gov.sa/english/

CH2M Hill International and CEG. (1982). Executive Plans for Dammam Metropolitan Area - Planning Systems Report-Appendix. Prepared for Eastern Province Amanah, MOMRA, Kingdom of Saudi Arabia.

CNU. (2001). Charter of the New Urbanism. Congress for the New Urbanism (CNU). Retrieved October 25, 2012, from http://www.cnu.org/sites/www.cnu.org/files/charter_english1.pdf

Cohen, B. (2006, January-April). Urbanization in developing countries: current trends, future projections and key challenges for sustainability. Technology in Society, 28(1-2), 63-80. http://dx.doi.org/10.1016/j.techsoc.2005.10.005

Eastern Province Amana, KSA. (2014). Inauguration of an Urban Observatory in Dammam Metropolitan Area. Retrieved from http://www.eamana.gov.sa 
European Environment Agency. (2006). Urban sprawl in Europe. EEA Report No. 10/2006. Retrieved from $\mathrm{http} / / /$ reports.eea.europa.eu/ eea_report_2006_10/en/eea_report_10_2006.pdf

Garba, S. B. (2004). Managing urban growth and development in the Riyadh metropolitan area, Saudi Arabia. Habitat International, 28, 593-608 http://dx.doi.org/10.1016/j.habitatint.2003.10.008

Ifatimehin, O., \& Musa, S. D. (2008). Application of Geoinformatic Technology in Evaluating Urban Agriculture and Urban poverty in Lokoja. Niger. J. Geogr. Environ., 1, 21-23.

Lambin, E. F., Geist, J. H., \& Lepers, E. (2003). Dynamics of Landuse and Landcover in Tropical Regions. Annual Rev. Environ. Resources, 28, 205-241. Retrieved from http://www.aginternetwork.net/whalecomarjournals.annualreviews.org/whalecom0/doi/pdf/10.1146/annurev .energy.28.050302.105459

Ministry of Agriculture, KSA. (1999). Fishing Statistics in the Kingdom.

Ministry of Petroleum and Mineral Resource, KSA. (1982) Saudi Aerial Images.Space Surveying Department. 1982.

MOMRA-KSA, Ministry of Municipality and Rural Affairs, Saudi Arabia. (2007). Local and Action Area Plans for Cities of Dammam Metropolitan and Governorates of Qatif and Ras-Tanura. Prepared for Eastern Province Amanah, MOMRA, Kingdom of Saudi Arabia.

MPMR, KSA. Ministry of Petroleum and Mineral Resource, KSA. (1982). Satellite Image for Eastern Province, MPMR, Space Surveying Department.

Quick Bird. (2003). Satellite Image for Dammam Metropolitan Area.

Roy, M. (2009). Planning for sustainable urbanization in fast growing cities: mitigation and adaptation issues addressed in Dhaka, Bangladesh. Habitat International, 33(3), 276-286. http://dx.doi.org/10.1016/j.habitatint.2008.10.022

Shen, L.-Y. et al. (2011). The application of urban sustainability indicators: a comparison between various practices. Habitat International, 35(1), 17-29. http://dx.doi.org/10.1016/j.habitatint.2010.03.006

Ujoh, F., Kwabe, I. D., \& Ifatimehin, O. (2010, May). Understanding urban sprawl in the Federal Capital City, Abuja: Towards sustainable urbanization in Nigeria. Journal of Geography and Regional Planning, 3(5), 106-113. Retrieved from http://www.academicjournals.org/JGRP

UN DESA. (2014). World Urbanization Prospects: The 2014 Revision. Population Division, Department of Economic and Social Affairs, United Nations Secretariat.

UN, Economic and Social Council. (2014). Effective governance, policymaking and planning for sustainable urbanization. Report of the Secretary-General. E/2014/67.

UN. (2013). World Economic and Social Survey 2013. United Nations publication, Sales No. E.13.II.C.1).

UN-Habitat and DID, UK. (2002). Sustainable urbanization: achieving Agenda 21. Nairobi, 2002.

UN-HABITAT. (2001). The State of the World Cities - 2001.

\section{Copyrights}

Copyright for this article is retained by the author(s), with first publication rights granted to the journal.

This is an open-access article distributed under the terms and conditions of the Creative Commons Attribution license (http://creativecommons.org/licenses/by/3.0/). 